\title{
LETRAMENTO EM LÍNGUAS ESTRANGEIRAS NO \\ BRASIL: O PROJETO BRAFITEC E SUA RELAÇÃO FOS/ FOU
}

\section{LITTÉRATIE EN LANGUES ÉTRANGĖRES AU BRÉSIL: LE BRAFITEC EN TANT QUE PROJET FOS/FOU}

Joice Armani Galli/LENUFLE/UFPE ${ }^{1}$

\section{RESUMO}

Concebendo-se a inserção social do sujeito como condição sine qua non para o exercício de sua cidadania, propomos no presente artigo a discussão de políticas públicas linguísticas que garantam formação integral para além do mercado capitalista, que o determina como mero reprodutor. A proposição de projetos linguístico-culturais deve implicar esse ator social como agente transformador do contexto que o circunda, gerando reflexões e ações que inovem o pensamento contemporâneo em termos de produção. Dadas as atuais circunstâncias em que se discute a validade das licenciaturas, a temática relativa ao desenvolvimento dos estudos superiores, particularmente nas Letras e mais especificamente nas Línguas Estrangeiras - LE, em que o senso de criação da linguagem foi postergado em detrimento do imediatismo aplicacionista, é urgente rever a formação universitária no Brasil. Considerando a gravidade em banalizar preceitos primários da constituição do sujeito inserido historicamente em sua produção discursiva, o presente artigo busca articular os pilares científicos: formação, pesquisa e extensão em sua relação com a sociedade civil, uma vez que o conhecimento, como elemento libertador, deveria ser direito de todos. Preconizando, portanto, o acesso linguístico através do letramento crítico em LE, discorreremos sobre o programa federal Idiomas sem Fronteiras - IsF, mais particularmente o Francês sem Fronteiras - FsF e sua interface com o convênio bilateral BRAFITEC, além do fomento a projetos de pesquisa

1 Doutora em Letras pela Universidade Federal do Rio Grande do Sul. Email: armani.galli@ via-rs.net e joicearmanigalli@gmail.com 
de pesquisa na área das linguagens. Serão analisadas as reverberações da formação específica do francês - FOS e da formação universitária FOU na preparação de futuros intercambistas à luz de teóricos como Mangiante \& Parpette (2012). Os resultados levam a compreender a pertinência na proposição de metodologias contextualizadas para formação e pesquisa universitárias no Brasil.

PALAVRAS-CHAVE: Línguas Estrangeiras; Políticas Públicas; FOU; Letramento.

\section{RÉSUMÉ}

Compte tenu du fait que l'insertion sociale du sujet se présente comme condition sine qua non pour la réalisation de sa citoyenneté, nous proposons à travers cet article la discussion de politiques publiques linguistiques qui assurent la formation intégrale au-delà du marché capitaliste, qui le détermine comme un tout simple reproducteur. La proposition des projets linguistiques et culturels doit prévoir l'implication de ce sujet comme un véritable agent de transformation de la pensée contemporaine, ce qui engendre la réflexion et la proposition des actions innovantes au niveau du marché de production. Etant donné les circonstances actuelles sur la légitimité de licences, le sujet concernant le développement des études supérieures au Brésil, en particulier pour les Lettres et plus encore pour les Langues Étrangères - LE, où il y a eu toujours la réduction à l'applicationnisme de langues, il est urgent que la formation universitaire soit mise au point. En sachant que la banalisation de cette formation de base n'est pas sans conséquences surtout pour la constitution d'un sujet inscrit dans un contexte historique précis dans sa production discursive, le présent article cherche à articuler les piliers scientifiques, à savoir : la formation, la recherche et 'l'extensão' dans son rapport avec la société, vu que le droit aux études devrait être assuré à tous. Ayant à la base, ainsi, l'accès linguistique à travers la littératie critique en LE, on parlera sur le programme fédéral Idiomas sem Fronteiras - IsF, plus précisément sur le Français sans Frontières - FsF, son interface à la convention bilatérale BRAFITEC, et la réalisation des projets de recherche dans les sciences du langage. L'analyse se fera autour des retentissements de la formation spécifique du français - FOS et la 
formation universitaire - FOU dans la préparation de futurs candidats

: au programme de mobilité à partir de théoriciens tels que Mangiante \& Parpette (2012). Les résultats permettent de comprendre la pertinence dans la proposition des méthodologies contextualisées pour la formation et la recherche dans les études supérieures au Brésil.

MOTS-CLES: Langues Étrangères; Politiques Publiques; FOU; Littératie.

\section{INTRODUÇÃO}

A democratização do conhecimento encontra mão dupla na repercussão que estabelece com a sociedade e talvez seja esta justamente a razão pela qual não interesse às classes conservadoras discorrer sobre políticas públicas. Menos ainda discutir políticas linguísticas, já que a língua é por excelência a entrada privilegiada do saber.

Nesse sentido, pretendemos desenvolver no presente artigo reflexões acerca de processos discursivos em línguas estrangeiras (LE), cujo elemento desencadeador seja o letramento, entendido como constituição do sujeito em sua expressão linguística, artística e literária em línguas. Erigido nos princípios preconizados, portanto, pelo letramento em LE e pela articulação gerada entre formação, pesquisa e extensão na vida universitária, comungamos igualmente das teorias em torno do FOS e FOU - Français sur Objectif Scientifique e Français sur Objectif Universitaire para apresentar o projeto de pesquisa e extensão que intitula a presente produção científica.

Pressupondo-se que a universidade pública seja espaço de reflexão, apresentaremos algumas possibilidades de ação para o desenvolvimento de políticas públicas linguísticas, sobretudo no atual contexto de grandes mudanças sociais, já que os últimos anos foram marcados por importantes transformações nas áreas das línguas e particularmente no que concerne às LE. Algumas das razões para explicar tais circunstâncias encontram eco no fato de que a globalização e os fluxos migratórios em escala planetária trouxeram significativas consequências nos processos de ensino e aprendizagem de línguas. Nesse contexto, nasce em 2010 o programa federal brasileiro Ciências sem Fronteiras - CsF, vindo posteriormente a desenvolver um eixo linguístico. No processo de internacionalização vislumbrado pelo CsF, surge a proposta experimental do inglês sem fronteiras. Algum tempo depois outras línguas vêm a somar-se ao referido 
programa que, aproveitando a sigla de Inglês sem Fronteiras - IsF, passa a ser chamado Idiomas sem Fronteiras - IsF, para descontentamento de : muitos que veem no emprego de 'idiomas' um forte vínculo comercial.

Em termos de políticas públicas, a gestão de programas e projetos linguísticos não pode ser comparada àquela empregada por empresas privadas, tampouco pelos treinamentos de 'coach' tão em moda atualmente. A universidade pública brasileira tem papel primordial na promoção do conhecimento enquanto fonte de diversidade e inclusão, inovação e pesquisa.

Assim, dando continuidade ao histórico do IsF, a partir dos anos seguintes, outras línguas como o espanhol e o italiano passam a integrar o referido programa federal. $O$ francês, no entanto, só veio a existir em 2014, sob o registro de Français sans Frontières - FsF. Desde sua criação, a UFPE tem participado ativamente das discussões junto ao MEC (Ministério da Educação e da Cultura), para o desenvolvimento deste programa linguístico nacional inédito na história de línguas do Brasil. Sob tal perspectiva, o presente artigo traz à discussão a inserção da língua francesa como espaço de experimentação para implementação de políticas públicas ao articular estudantes da área das humanas com alunos oriundos das exatas, na promoção dos estudos superiores.

Ainda que anterior ao dito programa, o projeto FOS/FOUBRAFITEC acabou por consolidar a prática da ação extensionista promovida pelo grupo de pesquisa em francês do Centro de Artes e Comunicação - CAC como ação inicial do FsF na federal pernambucana. Dessa forma, consideramos adequado discorrer inicialmente sobre o programa de mobilidade BRAFITEC; tratando a seguir do surgimento da proposta como metodologia de pesquisa em LE, para propormos ao final a apresentação de uma sequência didática sobre o sistema educativo francês, como módulo formativo da preparação realizada aos futuros intercambistas do programa FsF.

\section{O BRAFITEC como programa de mobilidade internacional}

Criado em 2003, o BRAFITEC - BRAsil France Ingénieurs et TEChnologie - é um programa de mobilidade financiado por ambos governos, permitindo às grandes escolas francesas de engenheiros e às universidades brasileiras a realização de convênios. Tais acordos 
visam trocas científicas entre estudantes e professores da referida área. Do lado francês, o programa tem apoio da Conférence des directeurs des écoles françaises d'ingénieurs (CDEFI) e, do brasileiro, da Comissão de Aperfeiçoamento de Pessoal do Nível Superior (CAPES), agência de fomento conhecida pelo incentivo a projetos no Brasil.

Considerando que se apropriar ${ }^{2}$ da língua francesa configura-se como uma das condições para postular sua candidatura ao programa, o CAC, por meio do grupo de pesquisa LENUFLE - Letramento 'Numérique' do Francês como Língua Estrangeira, oferece a formação linguística e cultural do francês, com vistas a obter o nível A2, do 'Quadro Europeu Comum de Referências para as Línguas', conhecido tão somente por « Cadre » (2001), como requisito oficial da CAPES ${ }^{3}$. As aulas acontecem durante $4 \mathrm{~h}$ por semana durante cinco meses (de novembro a maio). A formação totaliza 120 horas ( $96 \mathrm{~h}$ de FOS $+24 \mathrm{~h}$ de FOU), sendo acrescidas 60 horas de preparação de material didático, elaboração de provas e reuniões pedagógicas, seja entre os bolsistas de língua francesa, seja entre os professores das engenharias e do design responsáveis por cada projeto BRAFITEC.

Trata-se, portanto, de um projeto que perfaz 180 horas e que tem ao total nove meses de duração. Designado por FOS/FOU-BRAFITEC/UFPE - 2015/2016, ao longo dos sete últimos anos em que ocorre nesta IES, tem a chamada do edital por parte do Centro de Tecnologias e Geociências - CTG no mês de setembro. Os alunos submetem assim sua candidatura por meio de projeto aos professores pesquisadores de suas respectivas áreas e, no mês seguinte, geralmente em outubro é feita a seleção dos projetos. Somente após estes procedimentos, o CAC/LENUFLE inicia a formação do binômio língua-cultura no contexto universitário.

Nesse sentido, percebe-se que o intercultural como aspecto promotor do letramento em LE já se encontra inscrito desde o título do projeto. Em todas edições anteriores, respeitamos o calendário francês, no qual o ano escolar não corresponde ao calendário civil como acontece no Brasil. Passemos a seguir a discorrer sobre as concepções teórico-metodológicas que subjazem o presente projeto.

2 Preferimos explicitamente o termo 'apropriar-se ' a 'dominar', por compreendê-lo como mais adequado ao que preconiza o letramento em $\mathrm{LE}$, que não entende a língua como domínio, mas como processo de interação em relação ao outro e a si mesmo.

3 Cabe ressaltar que, no último ano, o corte de verbas levou à redução de bolsas de estudo, bem como à elevação de nível linguístico solicitado. Em março de 2016, o nível demandado passou a ser B1, trazendo inúmeras reverberações ao projeto em tela, que teve de se adequar pedagógica e academicamente para atender a este imperativo. 


\section{FOS/FOU e suas reverberações enquanto projeto de pesquisa}

Perspectivado sob uma lógica que tenta fugir aos ditames do sistema de produção do capital e tendo por base o letramento crítico em LE, o referido projeto teve início em julho de 2010 na UFPE. Quanto à base teórica, pensamos ser pertinente comentar o uso de letramento e/ou letramento crítico em LE, já que não entendemos letramento sem sua criticidade. Vistos assim como sinônimos, pensamos, no entanto que o letramento crítico aqui marcado em algumas referências traz maior apelo ao conceito plural que a dinâmica das LE se inscreve. O próprio surgimento do programa linguístico "Inglês sem Fronteiras" revela aspectos percucientes da sociedade brasileira em sua relação com as LE. Ao acontecer posteriormente à criação do programa CsF, indica ainda o caráter acessório impingido às línguas desde sua presença na instrução oficial no Brasil. O tom complementar atribuído a um conhecimento de mundo revelado pelos processos de ensino-aprendizado de uma LE aponta desde já o entendimento somente utilitarista da língua, restando apenas ao falante nativo o bom 'domínio' da mesma. Acrescente-se o fato de parecer ser consensual entender que língua estrangeira é igual à língua inglesa. Tais constatações reafirmam uma tradição nos estudos brasileiros no tocante à pesquisa em $\mathrm{LE}$, os quais encerram igualmente a contradição do que seja oportunizar o conhecimento do outro pelo processo engendrado na alteridade linguística através de outras línguas que não somente o inglês.

Daí a pertinência de trabalharmos LE sob a ótica transversal, concebendo-a como constituição formativa do sujeito historicamente determinado por uma representação ainda bastante relacionada a um imaginário que a estigmatiza como signo de estratificação social. O ensino e aprendizado de línguas tem de ser revisto em sua concepção teórica e metodológica. Bakhtin (1984) afirma que a língua realiza-se no enunciado, em uma relação recíproca do acontecimento linguístico e literário, já que " $\mathrm{A}$ língua penetra na vida através enunciados concretos (que a realizam), e é ainda através dos enunciados concretos que a vida penetra na língua (1984: 268)”. A língua, só se realizando na interação que efetua com o outro, impõe assim que noções relativas ao intercultural, ao letramento e à alteridade sejam discutidas. Tais circunstâncias deslocam o papel do professor da simples reprodução de materiais didáticos, convidando-o a se tornar um pesquisador e produtor de sentido em LE.

4 Original : "La langue penètre dans la vie à travers des énoncés concrets (qui la réalisent), et c'est encore à travers des énoncés concrets que la vie penètre dans la langue. $(1984: 268)$. Todas traduções neste artigo são responsabilidade nossa. 
Sob tal perspectiva, o projeto FOS-FOU/BRAFITEC encontra-se : em constante refazimento e a cada nova edição tenta garantir o exercício desse dialogismo linguístico do sujeito da linguagem. O legado da distinção estruturalista langue $x$ parole traz em tempos pós-modernos, mais do que em qualquer outro período dos estudos da linguagem, a necessidade de se revisitar a metodologia do ensino de LE através de conceitos menos dicotômicos e mais subjetivos, próprios à natureza cultural em que se situa o signo linguístico. Assim trabalhar língua significa trabalhar a intraduzibilidade que a riqueza humana apresenta em termos de comunicação cultural e social, conforme resultados apontados em Galli (2015), no tocante ao trabalho desenvolvido pela cartografia do FLE - Français Langue Étrangère, em Recife e Olinda.

Inscrito, portanto, sob a perspectiva de políticas públicas linguísticas e tendo igualmente por base os princípios preconizados pelo FOS - Français sur Objectif Spécifique, voltado preferencialmente para as áreas das engenharias e do design, o projeto foi se revisitando desde a primeira edição. Atualmente assume igualmente a modalidade do FOU - Français sur Objectif Universitaire, pelo entendimento sugerido por teóricos como Mangiante et Parpette. Tais estudiosos atentam para o olhar acadêmico que se deve lançar aos estudantes estrangeiros nas grandes 'écoles' de engenharia francesas:

A proporção sutil de estudantes alofones durante as aulas, suas dificuldades e seus fracassos, até mesmo o abandono de seus estudos interrogam a prática dos professores quanto a seus aspectos metodológicos, organizacionais e mesmo culturais. O lugar da língua de ensino no bem-sucedido desenvolvimento dos estudos universitários tornou-se não somente um tema de preocupação, mas também um campo de estudo. (2004: 18) ${ }^{5}$

5 Original: La proportion sensible d 'étudiants allophones au sein des classes, leurs difficultés, leurs échecs, voire 1 'abandon de leurs études, interrogent la pratique des enseignants dans ses aspects méthodologiques, organisationnels et même culturels. La place et le rôle de la langue d enseignement dans la réussite des études supérieures sont devenus non seulement un sujet de préoccupation, mais aussi un champ d 'étude (2004: 18). 
Elaborado assim para um público cujos objetivos são específicos, a concepção das aulas não pode prescindir da elaboração de materiais adequados a este contexto como atestam os membros do grupo de pesquisa que realizaram diferentes colaborações para a execução desde trabalho, como Rahissa Lima, Larissa Arruda, Jaqueline Oliveira, Sandro Aguiar e Weslane Silva. Tal configuração aponta um campo de estudo metodológico para a pesquisa de estudantes de Letras Licenciaturas no Brasil pelo aporte do letramento crítico em LE que tais jovens pesquisadores vivenciam. Consequentemente suas reflexões produziram a elaboração de materiais com as especificidades a serem aprendidas, já que "um dos aspectos maiores dessa integração reside em uma formação linguística sólida, adaptada às necessidades geradas por situações linguageiras exigentes” ${ }^{6}$ (MANGIANTE \& PARPETTE, 2012: 147)

Segundo Blanchet \& Chardenet (2011), a pesquisa contextualizada deve se debruçar sobre as variantes impostas pela cor local para o desenvolvimento de pesquisas linguísticas que deem conta da configuração científica contemporânea. Dessa forma, o laboratório LENUFLE busca ir além da mera introdução das TICE (Tecnologias da informação e da comunicação para o ensino) como ferramenta de trabalho. Busca-se uma abordagem que promova atividades de descoberta do FLE através da multidimensionalidade aportada pelas novas tecnologias. Por isso, apesentaremos a seguir a realização de um dos módulos FOU, conforme quadro que sintetiza as informações gerais dessa formação:

\section{FOS/FOU - BRAFITEC - UFPE MODULO FOU}

\begin{tabular}{|c|c|c|}
\hline 3 Séquences de 8h chacune & 4 Séances de 2h chacune & Durée totale 24 \\
\hline 1 - Á la Découverte & $\begin{array}{c}\text { Avant le départ - Un } \\
\text { nouveau monde }\end{array}$ & $8 \mathrm{~h}$ \\
\hline 2 - Le Voyage & $\begin{array}{c}\text { Avant le départ - La } \\
\text { demande de VISA }\end{array}$ & $8 \mathrm{~h}$ \\
\hline 3 - Á l'Arrivée & $\begin{array}{c}\text { Au début du séjour - Les } \\
\text { contacts }\end{array}$ & \\
\hline
\end{tabular}

6 Original : «L Lun des aspects majeurs de cette intégration réside dans une formation linguistique solide, adaptée aux besoins générés par des situations langagières exigeantes. (MANGEANTE \& PARPETTE, 2012 : 147). 
Consideramos que a preparação para a viagem de estudos tenha de contemplar necessariamente a descoberta de um novo mundo, os preparativos da viagem, como a solicitação do visto, para então aportarmos com a chegada e seus primeiros contatos na França. Elegemos aqui uma escola particular, a ENSTA/Bretagne - Ecole Nationale Supérieure de Techniques Avancées, da região bretã na França, forte polo naval pelas similitudes passíveis de serem feitas com o complexo de SUAPE, na região pernambucana.

Pensamos assim que seja interessante para a presente exposição discorrermos sobre a primeira parte desse módulo e sua atividade desencadeadora. Com vistas a ilustrar o projeto, apresentaremos a seguir a concepção da primeira unidade didática - UD - do módulo FOU.

\section{O sistema educativo francês}

A falta de correspondência entre os países em sua organização educacional impõe que projetos de internacionalização produzam conhecimento acerca desta diferença. Tanto institucionalmente quanto culturalmente a não equivalência diz respeito a reorganizar a situação de intercambista para o eficaz desenvolvimento dos estudos universitários no exterior. Nesse sentido, abordamos o sistema educativo francês como atividade inicial do módulo FOU, já que a presente temática parece-nos ser uma porta de entrada para o letramento em LE, proposta central do referido projeto.

Da mesma forma, o manuseio de 'documents authentiques et francophones' preparam o estudante para a descoberta de um novo horizonte cultural no campo dos estudos linguísticos, visto que, em termos de discurso e enunciado, noções privilegiadas pelo projeto, "não se aprende mais uma língua para desenvolver tão simplesmente um saber sobre ela, mas para agir com essa língua" 7, conforme afirma J.-J Richer (2008: 15). A proposta, portanto, de tarefas que apresentem o desvelamento deste novo mundo diminuirão as distâncias nas aulas de línguas. Tais discrepâncias impõem que sejam contemplados conteúdos e abordagens sobre as particularidades sociais e culturais quanto ao formato científico e acadêmico da vida universitária.

Trabalhar LE sob os princípios que regem um letramento crítico

7 Original : «qu 'on $\mathbf{n}$ `apprend plus une langue pour développer un savoir sur la langue, mais pour agir avec cette langue "( J-J RICHER, 2008 : 15). 
significa contextualizar as necessidades do público alvo, identificar : os aspectos positivos e negativos a fim de estabelecer os objetivos a : serem alcançados. $\mathrm{O}$ entendimento de projetos dessa natureza beneficia não somente os estudantes das Engenharias e do Design, que recebem a formação, mas igualmente e, sobretudo, já que estamos na área das linguagens, os futuros profissionais das Letras.

Segundo A. Martinet aprender uma LE, “[...] não é apenas colocar novas etiquetas em objetos conhecidos, mas habituar-se a analisar de outra forma o que faz o objeto da comunicação" ${ }^{8}$ (2003: 12), desenvolvendo uma verdadeira alteridade linguística, uma vez que, para interagir em LE, não é preciso traduzir palavra por palavra, mas conhecer as nuances que existem em uma língua, bem como o uso de expressões no interior de cada área. A visão intercultural permitirá fazer-se uma análise mais descentrada da gramática, colaborando na formação crítica do sujeito.

Os preceitos que subjazem esta prática pedagógica estabelecem uma dinâmica de produção e não mais de reprodução do fazer acadêmico. $\mathrm{Na}$ formação FOU, temos o primeiro módulo intitulado, 'À La Découverte', cujo objetivo geral é desvelar este novo universo cultural por meio de uma abordagem linguística contextualizada.

\section{A Unidade Didática - UD}

Considerando que já foram realizadas aproximadamente 100 horas de língua, seguindo a 'démarche' FOS, a cada aula pretende-se explorar conteúdos importantes como o sistema educativo francês, o conhecimento da distribuição geográfica da França e da escola parceira, bem como as atividades culturais desenvolvidas pela escola de acolhida. Descobrindose assim as peculiaridades da nova paisagem cultural, ensaiam-se projetos como a ação propositiva de cada aluno, já que ao final do módulo eles devem estar também apropriados desses conhecimentos no que tange a sua realidade e região brasileiras, a fim de apresentá-las em francês aos novos colegas estrangeiros.

Pode-se afirmar dessa forma que a competência intercultural acontece por meio do desenvolvimento de tarefas que oportunizam ao estudante estabelecer relações entre sua cultura e a que está sendo aprendida.

Vejamos a seguir informações específicas do I Módulo FOU:

8 Original : «[...] ce $n$ `est pas mettre de nouvelles étiquettes sur des objets connus, mais s'habituer à analyser autrement ce qui fait 1'objet de la communication linguistique » (MARTINET, $2003:$ 12). 
UNITÉ 1 - A LA DÉCOUVERTE - Un nouveau monde

\begin{tabular}{|c|c|c|c|}
\hline Séance 1 & Séance 2 & Séance 3 & Séance 4 \\
\hline $\begin{array}{c}\text { Connaître le } \\
\text { système éducatif } \\
\text { français }\end{array}$ & $\begin{array}{c}\text { Etre présenté à la } \\
\text { carte française }\end{array}$ & $\begin{array}{c}\text { Faire connaissance de } \\
\text { l'école partenaire }\end{array}$ & $\begin{array}{c}\text { Connaître } \\
\text { une activité } \\
\text { culturelle de } \\
\text { l'ENSTA/ } \\
\text { Bretagne }\end{array}$ \\
\hline 2h & & & $2 \mathrm{~h}$ \\
\hline
\end{tabular}

Para a apresentação da UD optamos por deixar o texto em língua francesa, no formato original do projeto por entendermos que esta seja talvez uma boa ocasião para sensibilizarmos nosso leitor ao texto francês. Ao utilizarmos um documento francófono sugerimos que a diversidade linguística seja desenvolvida ao longo da formação FOU. Dessa forma, consideramos igualmente pertinente observar como pode-se trabalhar a proposta a seguir, indicando as possíveis respostas dos alunos, no item 'Réponse' ou simplesmente R.

\section{Unité 1 - À LA DÉCOUVERTE}

Séance 1 : Connaître le système éducatif français $-2 \mathrm{~h}$

\section{Objectifs pragmatiques:}

- Avoir accès à un guide de comparaison sur l'éducation en France et au Québec ;

- Repérer les informations principales d'un document francophone ;

- Connaître les principaux sigles de son domaine dans le système français ;

- Interpréter un graphique.

\section{Objectifs linguistiques:}

- Emploi des différentes terminologies pour les certifications;

- Révision du Passé Composé pour accéder aux textes ;

- Repérage des sigles et leurs accords ;

- Utilisation des prépositions de pays ;

- Vérification de l'emploi des adjectifs de nationalité dans les noms propres;

- Révision du comparatif ; 
Objectifs socioculturels:

- La prise des notes à partir de l'exposé oral de l'enseignant ;

- Avoir une idée générale sur le principe de la laïcité, présent au système français depuis la fin du XIX Siècle ;

- Respecter les horaires de son cursus.

Documents adaptés utilisés :
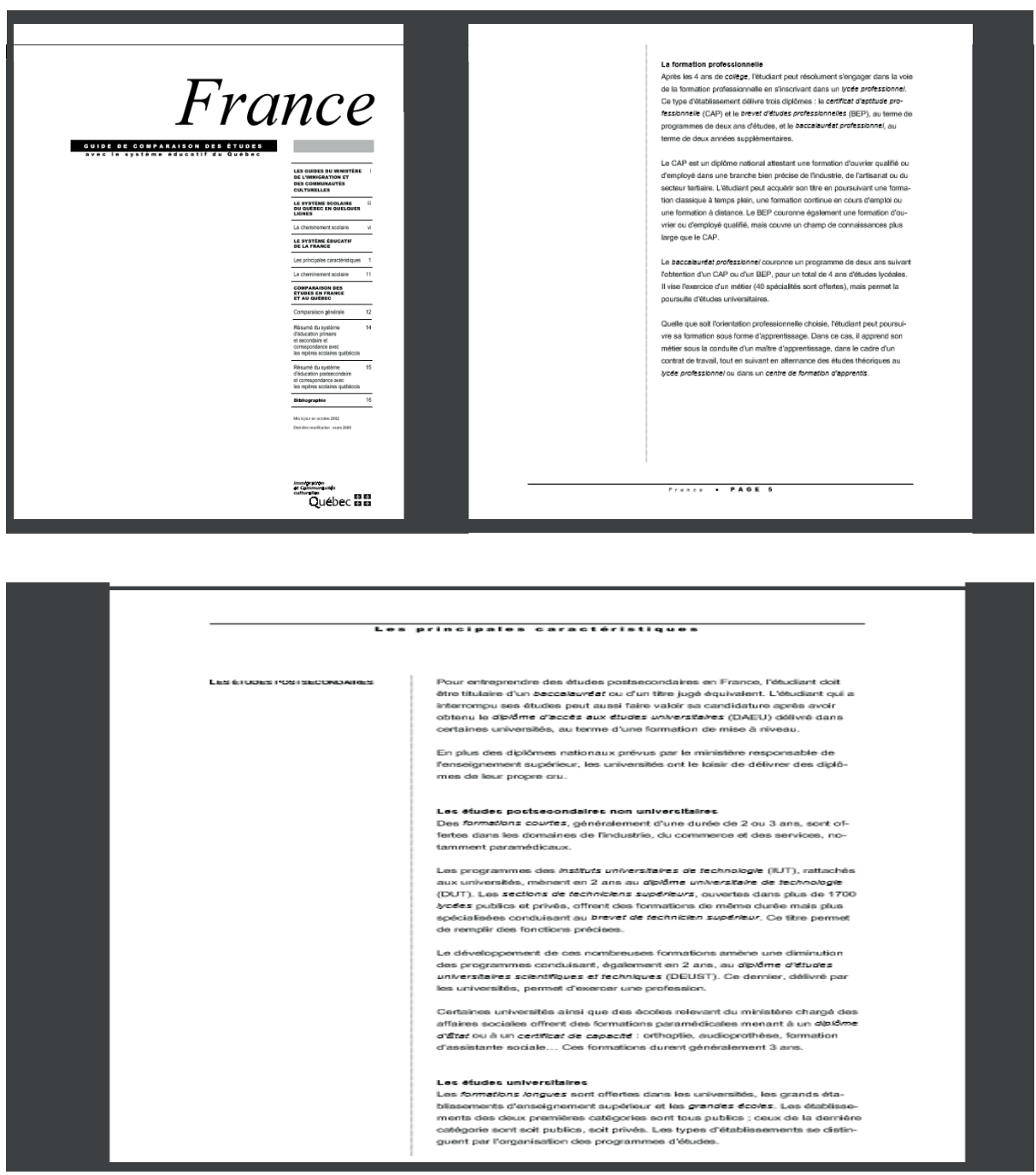

Un guide de consultation : http://collections.banq.qc.ca/ark:/52327/bs59502 Un graphique : http://mavoieproeurope.onisep.fr/la-voie-pro-en-europe/ france/ 
: Déroulement de la Première Séance : Suite à la distribution des

: documents indiqués, répondez aux questions suivantes : (travail collectif en groupe classe/ consignes à l'oral, en leur demandant de prendre des notes)

Activité 1 : Premier Document - Connaître un texte francophone sur le système éducatif. (durée totale $50 \mathrm{~min}$ )

a) Observez la couverture de ce Guide et dites à quoi il sert et à quel pays il concerne.

Réponse : C'est un Guide des Études et il concerne la France

b) Encore sur la couverture, vous trouvez des informations sur ce Guide. Quel est l'organisme qui le publie et quelle est l'année de sa dernière édition?

Réponse : Ministère de l'immigration et des communautés culturelles MICC - 2005

c) Ce ministère appartient à quelle région? Au Québec

d) Et cette région appartient à quel pays ? Au Canada

e) Suite au grand titre - France - nous avons une explication sur l'objectif principal de ce Guide. Depuis sa lecture, nous pouvons affirmer qu'il propose :

$$
\text { (x ) une comparaison ( ) une contestation }
$$

f) Tout en regardant le visuel de cette couverture, pourriez-vous caractériser l'image en bas et à droite.

Réponse: C’est le drapeau du Québec, il est caractérisé par la fleur de lys, qui représente la royauté française.

g) Nous avons donc un guide d'études comparatif entre un pays et une région, pourquoi ? A ce constat, pourriez-vous faire des hypothèses Réponse : Parce que le Canada est un pays bilingue, où on parle anglais et français. Cette région montre l'importance de la langue française.

h) Complétez les énoncés suivants :

Ce Guide propose une comparaison des études_en_France et_au_ Quebéc. i)

J'habite__au__Brésil, mais je vais étudier en__France. 
j) Lisant le sommaire, quelles sont les hypothèses concernant les objectifs de ce Guide. Donner des informations sur le système scolaire :

( ) canadien et français ( $\mathrm{X}$ ) québecois et français

Activité 2 : Deuxième et Troisième Documents - Compreendre les sigles employés en France dans son domaine. (durée totale $40 \mathrm{~min}$ )

a) Rélèvez les sigles présents dans le système éducatif français ; Réponse : CAP ; BEP ; DAEU ; IUT ; DEUST ;

b) Dans la rubrique "Les études postsecondaires " le DUT est un diplôme qui correspond à la licence en Génie au Brésil ?

$\operatorname{Vrai}(\quad)$ Faux $(\mathrm{x})$

c) Complétez: En France, les formations longues sont offertes dans les_universités_et les_grandes écoles__.

d) D’après la lecture de ce matériel, essayons de remplir le tableau ci-dessous :

\begin{tabular}{|ccc|}
\hline \multicolumn{4}{|c|}{ Reliez les notes à leurs definitions correspondantes : } \\
\hline 1$)$ & $16-20$ & $(3)$ Assez Bien \\
\hline 2$)$ & $14-15$ & $(1)$ Très Bien \\
\hline 3$)$ & $12-13$ & $(4)$ Passable \\
\hline 4$)$ & $10-12$ & $(2)$ Bien \\
\hline
\end{tabular}

Activité 3 : Projection du document au tableau - Exploitation et analyse du graphique :(durée totale $30 \mathrm{~min}$ ) 


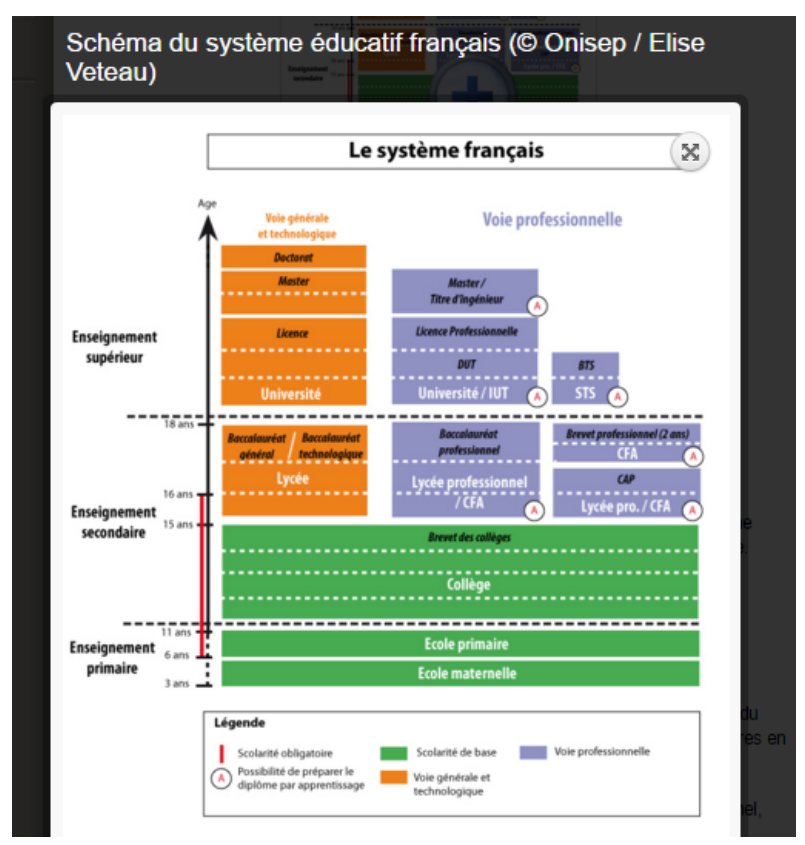

Source : http://mavoieproeurope.onisep.fr/la-voie-pro-en-europe/france/

a) Dans ce graphique, dites combien de couleurs il y en a ? R : Trois couleurs.

b) Vérifier vos hypothèses en caractérisant chaque couleur. R : Vert : l'enseignement primaire et secondaire ; orange et bleu : l'enseignement supérieur.

c) Dans les trois grandes lignes transversales, identifiez les noms de ces niveaux en France et dites s'ils correspondent aux grands axes dans le système éducatif brésilien. $\mathrm{R}$ : En France, il y a trois niveaux : le primaire, le secondaire et les études supérieures tout comme au Brésil.

d) La distribution verticale du graphique est faite à partir de quel niveau ? Est-ce que vous sauriez l'expliquer ? $\mathrm{R}$ : La division en deux est faite à partir de l'enseignement secondaire, parce que le système français présente à partir de ce niveau le choix pour les études supérieures.

e) A la verticale et à partir de l'identification des couleurs, dites quelle est la différence entre les deux axes. $\mathrm{R}$ : La différence est attribuée au choix général ou technologique, en orange et à la voie professionnelle, identifiée en bleu. 
f) Dans l'enseignement supérieur en France, nous avons les universités, les IUT - Instituts universitaires techniques et les STS - : Section de technicien supérieur. Est-ce qu'au Brésil nous avons ce genre de distribution au niveau de l'enseignement supérieur ? Non

g) La formation par la voie professionnelle aux lycées français correspond à l'enseignement technique au Brésil ? Justifiez votre réponse. Non, parce que la formation technique au Brésil est réalisée à l'enseignement secondaire et non pas dans le niveau supérieur.

h) Dans les études supérieures en France, et plus précisément dans la voie professionnelle, nous avons le DUT (diplôme universitaire de technologie) et le BTS (brevet de technicien supérieur). A partir de sa disposition sur le graphique, quelles hypothèses pourriez-vous faire à propos de cette certification ? R : La lecture du graphique permet d'affirmer que le diplôme est fourni par l'institut universitaire technique et le brevet par la section de technicien supérieur.

i) Le DUT est équivalent à la licence professionnelle d'un « tecnólogo » au Brésil, dites si cette affirmation est $(\mathrm{x}$ ) vraie ( ) fausse

j) A partir de l'analyse du graphique, combien d'années faut-il pour être titulaire d'un doctorat en France ? Et au Brésil ?R : Il faut trois années après le master ou le titre d'ingénieur en France, mais au Brésil il faut ajouter quatre ans au titre de master.

A introdução ao estudo que apresenta a distinção entre o sistema educativo brasileiro, o da região quebequense e o francês possibilita o entendimento de formas diversas de apreensão do conhecimento linguístico e cultural, contribuindo efetivamente para um projeto de internacionalização. Saliente-se que das cinco competências esperadas pelo "Cadre", compreensão oral e escrita - CO/CE e produção oral e escrita - PO/PE, além da competência intercultural, o mais importante nesse primeiro módulo não são certamente as produções/expressões oral e escrita, mas a apropriação deste conhecimento na sua competência intercultural. 


\section{ALGUMAS CONSIDERAÇÕES FINAIS}

Conceber o processo de ensino e aprendizagem através da alteridade pressupõe a interlocução com o outro, pressupõe trabalhar sob o prisma da cultura. Nesse sentido, o programa de mobilidade BRAFITEC representa uma força na educação superior, cujo desenvolvimento sobre o conceito de internacionalização tem repercussões decisivas na forma de realização do processo que ocorre em paralelo, ou seja, sua interculturalização. O que nos convida à reflexão nesse processo é o princípio da alteridade sobrepujado pelo desafio sobre o qual se debruça a proposta de um programa de intercâmbio, já que a mera mobilidade não garante internacionalização.

Nesse contexto, pensamos que a dificuldade maior não está somente em colocar os pés no estrangeiro, mas colocar-se estranho em seu próprio país, em um processo contínuo de interlocução com o outro. $\mathrm{Na}$ elaboração desta formação na federal pernambucana, ao longo dos últimos anos, o trabalho cultural subjacente ao preparo das aulas e à manipulação com documentos autênticos torna evidente que a intraduzibilidade de muitos conceitos apresentados aos futuros intercambistas é a experiência linguística dessa alteridade. Não se trata absolutamente de fazer operacionalizar-se um modelo eurocentrista de internacionalização, mas de saber 'movimentar-se' nesse novo mundo, já que seu processo de estruturação passa necessariamente por este olhar para o outro.

A título de conclusão, pode-se afirmar que a eficácia de políticas públicas linguísticas apresenta forte relação com o desenvolvimento de projetos que visem ao letramento crítico em LE. Tais projetos devem ser concebidos sob a ótica plural da cultura humana, além de estarem devidamente contextualizados, respeitando a diversidade e a inclusão. Entendemos assim que a elaboração de projetos que visam a integrar os pilares universitários conduz a caminhos democráticos e libertadores para o processo de ensino e aprendizado de línguas no Brasil enquanto pesquisa e formação universitárias. 


\section{REFERENCIAS:}

AUBIN, S. \& GALLI, J. Motiver à l'enseignement du français au Brésil. In : Le Français Dans Le Monde. Numéro 397/Janvier-Février. Paris: CLE International, 2015, p. 34 et 35.

ASDIFLE, Les Cahiers de l'. Y a-t-il un français sans objectif(s) spécifique(s). Actes des 29 et 30 rencontres, Mars Paris 2002 et Octobre Grenoble 2002.

ALBUQUERQUE-COSTA. Francês para objetivo universitário (FOU) na FFLCH/SP: formação linguística e discurso universitário para alunos que preparam intercâmbio com a França. Revista Estudos Linguísticos. São Paulo, 41 (2): p. 433-442, maio-agosto 2012.

. Ensino do francês para objetivo universitário (FOU): um dispositivo a distância de formação aux savoir-faire académiques para estudantes universitários que se preparam para estudar em universidades francesas. Revista Intercâmbio, V. XXIII : 47-63. São Paulo: LAEL/ PUCSP, 2011.

BAKHTINE, M. Esthétique de la création verbale. Paris : Editions Gallimard, 1984.

CARRAS et al. Réussir ses études d'ingénieur en français. Grenoble : PUG/FLE, 2014.

CONSEIL DE LA COOPÉRATION CULTURELLE - Comité de l'Éducation. Un cadre européen commun de références pour les langues : apprendre, enseigner, évaluer. Strasbourg : Didier, 2005.

CUQ, Jean-Pierre. Dictionnaire de didactique du français: langue étrangère et seconde. ASDIFLE. Paris : CLE International, 2003.

CUQ, J-P \& GRUCA, Isabelle. Cours de didactique du français langue étrangère et seconde. Grenoble: PUG, 2005.

DE CARLO, Maddalena. L'interculturel. Didactiques des langues étrangères. Paris: CLE International, 1998. 
: GALLI, J. A. SANTOS, L. Tornar-se professor de francês no Brasil : a : experiência do projeto 'Les Crabes' para a implementação de políticas públicas linguísticas. Cadernos de Letras da UFF: Niterói, numéro 53, 2016, p. 379-401. http://www.cadernosdeletras.uff.br/index.php/ cadernosdeletras/article/view/271/171

GALLI, J. A. A noção de intercultural e o ensino-aprendizagem de línguas estrangeiras no Brasil: representações e realidades do FLE. Revista EntreLínguas, volume 1, número 1 ISSN: 2447-4045, 2015. http://seer. fclar.unesp.br/entrelinguas/article/view/8055

A perspectiva contextualizada para futuros profissionais de FLE. Anais do VIII SELIMEL. Campina Grande/UFCG, 2013. http:// anaisselimelesiel.webnode.com/edicaoatual/

O sistema de avaliação de proficiência em leitura em francês como língua estrangeira no Rio Grande do Sul: a prova, os candidatos e o produto de leitura. Porto Alegre, 2004. Tese (Doutorado em Linguística). Programa de Pós-Graduação em Letras, Universidade Federal do Rio Grande do Sul.

KHOURY, Z. A. O ensino da língua francesa para fins específicos e universitários na UFU. Anais do SILEL. Volume 3, Número 1. Uberlândia : EDUFU, 2013.

MANGIANTE, J.-M., PARPETTE, C. Le français sur objectif universitaire : de la maîtrise linguistique aux compétences universitaires. Synérgies Algérie. Numéro 15, 2012, p. 147-166.

. Le français sur objectif universitaire. Grenoble: PUG, 2011.

Le français sur objectif spécifique : de l'analyse des besoins à l'élaboration d'un cours. Paris: Hachette, 2004.

MANGIANTE, J.-M. Vers un référentiel de formation linguistique pour les étudiants étrangers à partir de la construction de corpus professionnels. In : BERARD, E. et BORG, S. (éds.) Terres de FLE 2. Besançon: CLA, Université de Franche-Comté, 2009, p. 19-30. 
MANGIANTE, J.-M. Français de spécialité ou français sur objectif spécifique :deux démarches didactiques distinctes. Revista Investigación. : Instituto Pedagógico de Caracas, 2006, p. 137-151.

MARTINET, A. Eléments de linguistique générale. Paris : Collection Armand Collin, 2003.

MOULHRON-DALLIES, F. Enseigner le français à des fins professionnelles. Didier, Paris, 2008.

RICHER, Jean-Jacques. Le français sur objectifs spécifiques (F.O.S.) : une didactique spécialisée ? Synérgies Chine. Nnuméro 3, 2008, p. 15-30.

SITOGRAPHIE :http://collections.banq.qc.ca/ark:/52327/bs59502

http://mavoieproeurope.onisep.fr/la-voie-pro-en-europe/france/ 